\title{
Investimento Estrangeiro em Renda Variável e Taxa de Câmbio: relações no período 1999- 2012 para a economia Brasileira
}

\author{
Mirian da Silva Matos ${ }^{1}$ \\ Gustavo Inácio de Moraes²
}

Resumo: Os fluxos de capitais externos para investimento em carteira no Brasil tem se elevado nos últimos anos. Na década de 1990 o investimento estrangeiro foi predominantemente para renda fixa, e seu influxo exerceu influências sobre o câmbio. Na década seguinte este foi superado pelo investimento para renda variável. O objetivo deste trabalho é verificar se existe uma relação entre investimento estrangeiro em renda variável e taxa de câmbio, compreendendo as influências que exercem simultaneamente com Ibovespa e diferencial da taxa de juros, no período iniciado com a liberação do câmbio para flutuante em 1999, até 2012. Os resultados para o vetor auto regressivo e o teste de causalidade de Granger apontam para uma relação de causalidade da bolsa sobre o câmbio nos períodos de queda do Ibovespa, mas estes coeficientes ainda são inferiores aos do diferencial de taxa de juros.

Palavras-Chave: Investimento estrangeiro em carteira; variação cambial; Ibovespa; Brasil; vetores auto-regressivos.

JEL: C32, E44, Go1. 


\title{
Foreign Direct Investment in Equities and Exchange Rate: 1999-2012 Relations for the Brazilian Economy
}

\begin{abstract}
Capital flows for portfolio investment to Brazil have risen in recent years. In the 1990 s foreign investment was predominantly to fixed income, and this inflow has influenced exchange rate. In the next decade the fixed income flow was overcome by investment in equities. The objective of this paper is verify if exist a relationship between foreign investment in equities and exchange rates, including the simultaneous influences between these and Ibovespa with interest rate differential, in the period beginning with the release of floating exchange rate in 1999 until 2012. The results for auto regressive vector and Granger causality test indicate a causal relationship between equities and exchange rate in periods of devaluation of Ibovespa, but these coefficients remain lower than that of interest rate differential.
\end{abstract}

Keywords: Foreign portfolio investment; exchange rate variation; Ibovespa; Brazil; Vector autoregressive.

JEL: C32, E44, Go1.

\section{Introdução}

O investimento externo para renda fixa pode ser estimulado a ingressar ou a evadir-se, dentre outros instrumentos, através da determinação da taxa de juros, da formação de expectativas de câmbio estável e com a flexibilização de leis e regulamentações, garantindo à autoridade monetária certa influência sobre seu fluxo. No entanto, de acordo com números publicados pelo Banco Central do Brasil, o ingresso de investimento estrangeiro para renda variável (IERV) tem se tornado cada vez mais significativo na Conta Capital e Financeira, passando a superar IERF na primeira década de 2000.

Uma vez que o investidor externo passa a se concentrar na renda variável, os fatores internos ponderados por estes investidores para decidir pelo ingresso ou saída se tornam outros, e a autoridade monetária passa a influenciá-los de forma diferente. Tendo em vista este novo cenário macroeconômico, a questão que se impõe é se teria o IERV efeitos sobre o câmbio mais significativos do que as demais transações com moeda estrangeira, em especial sobre o IERF, que era a predominante na década de 1990.

Além da ótica macroeconômica, recentemente foram publicados estudos visando identificar o comportamento do mercado financeiro, por autores 
como Meurer (2005) e Franzen et.al. (2009). Eles observaram que o câmbio é um fator considerado pelos investidores externos para tomada de decisão, sendo parte da explicação do fluxo.

No contexto atual, uma das preocupações para promover o crescimento econômico tem sido a desvalorização do Real frente a outras moedas, por dar mais competitividade ao setor exportador. Se for verificado que a oscilação cambial é principalmente afetada pelo IERV, os fatores que determinam este fluxo poderiam ser estudados como ferramentas de política econômica, deixando de ser um campo de interesse apenas da parte especulativa do mercado financeiro. Um exemplo mais extremo é o caso da Malásia, que fechou sua Conta Capital após a crise asiática de 1997 e, segundo Kaplan e Rodrik (2001), teve uma recuperação econômica mais rápida que os demais países afetados pela crise na Ásia, com menor declínio no nível de empregos e salários.

O presente estudo objetiva verificar se o investimento estrangeiro para renda variável exerce efeitos sobre o câmbio estatisticamente significativos, inclusive comparando com o peso que o diferencial de taxa de juros exerce pelo investimento em renda fixa. Pretende-se ainda analisar se o fluxo de IERV apresenta relação de causalidade estatisticamente significativa sobre a variação do índice da Bolsa de Valores Brasileira - Ibovespa, e se estas relações de causa e efeito podem ser identificadas entre variações no fluxo de IERV, no câmbio e no Ibovespa. O estudo proposto seria uma continuidade dos realizados para a década de 1990, e também uma ótica diferente de causa e efeito com relação aos trabalhos mais recentes, pós ano 2000.

O artigo, além desta introdução, é composto por outras quatro seções. Uma seção de revisão da literatura, que focaliza o fluxo de capitais na década de 1990 e sua importância no desenvolvimento das economias emergentes, bem como no aumento de sua vulnerabilidade e na experiência brasileira com investimento externo. Outra seção compreende a descrição da metodologia empregada, o vetor auto-regressivo - VAR, sendo que a quarta seção, subsequente, explicita os alcançados. Uma última seção constrói considerações finais.

\section{Revisão de Literatura}

A última década do século XX pode ser considerada um momento de extrema expansão do passivo externo das economias emergentes. Segundo Athukorala e Rajapatirana (2003), o boom do fluxo de capital da primeira metade da década de 1990 foi uma combinação de fatores de demanda e de oferta. Pelo lado da demanda por crédito, houve uma sensível melhora das oportunidades e condições de atração dos países em desenvolvimento, e pelo lado da oferta estão aqueles relacionados à redução da taxa de juros nas economias desenvolvidas. 
Do total anual direcionado às economias emergentes entre 1990 e 1997, praticamente três quartos foram para os países da Ásia e da América Latina. A partir de 1993 o montante da Ásia passou a superar o da América Latina com grande margem, se distanciando ainda mais com a crise do México em 1994 (Athukorala e Rajapatirana, 2003). Este quadro se reverteu apenas em 1997, quando a Ásia sofreu uma abrupta fuga de capitais.

A diferença entre os influxos para as economias asiáticas e para as latino-americanas, de acordo com Ito (2000), é que as primeiras receberam principalmente investimento estrangeiro direto (IED), enquanto as latino-americanas tiveram forte entrada de investimento de portfólio. Além do ingresso de IED nas economias asiáticas, a taxa de poupança doméstica é bastante elevada, e a de investimento privado e governamental é ainda maior, o que permitiu a essas economias ingressarem em um círculo virtuoso de crescimento no início da década de 1990.

Ainda que grande parte deste fenômeno seja justificada pelas reformas econômicas e políticas promovidas internamente nestes países, Calvo et. al. (1993) afirma que este não é o único motivo, mas que também concorreria para tal outros fatores, externos às economias, relacionados a mudanças nas taxas de juros internacionais, níveis de liquidez e regulação que reduziram custos de transação.

Reforçando tal percepção, Agénor (1998) defende que o aumento do influxo de capitais para os países da América Latina e do Leste Asiático na primeira metade da década de 1990 deve-se principalmente às baixas taxas de juros praticadas pelos Estados Unidos.

Para as economias latino-americanas, o ingresso de capital estrangeiro as afeta pelo menos, de quatro formas (Calvo et al., 1993). De acordo com o autor, primeiro sob a forma de um aumento de liquidez eleva o nível de consumo e gera pressões inflacionárias. Segundo, está associada à apreciação cambial na maioria dos países. Seus bancos centrais, na tentativa de atenuar a valorização da moeda doméstica no curto prazo, com frequência começam a comprar parte do influxo de divisas e injetar moeda na economia. Para esterilizar a emissão de moeda, emitem-se mais títulos públicos que exigem taxas de juros superiores, elevando o diferencial de taxa doméstica-externa e agravando a situação fiscal com mais encargos pela dívida pública. E, em quarto lugar, o influxo de capitais emite sinais aos participantes do mercado financeiro mundial, atraindo mais capital especulativo que por vezes culminam em bolhas.

Ainda que o influxo de capitais proporcione aumento da taxa de crescimento do PIB, existe um momento em que suas consequências podem tornar sua entrada indesejável. Nesse particular, Calvo et.al. (1993) enumera três aspectos que devem ser observados. Primeiro, a entrada de capitais está tipicamente associada à apreciação da taxa de câmbio real e ao aumento de sua volatilidade, o que inevitavelmente afeta as exportações. Como as economias 
latino-americanas geralmente têm seu desenvolvimento tecnológico puxado pelo setor exportador, o crescimento econômico pode ficar comprometido se o governo não adotar uma política intervencionista. Segundo, o influxo de capitais pode não ser bem intermediado e acabar resultando em má alocação de recursos. Terceiro, o capital especulativo pode retornar em curtíssimo prazo, possivelmente provocando uma crise financeira doméstica. Edwards (1998) compartilha dessa visão.

Neste mesmo sentido, Cardoso e Goldfajn (1998) também avaliaram a importância de se utilizar diferentes esquemas de controles de capitais ao estudar o período de 1983 a 1995, caracterizado por dificuldades macroeconômicas e crises de balanço de pagamentos. Os autores constataram que o IED não foi afetado, mas os demais fluxos para renda variável e renda fixa foram sensíveis às condições nacionais e internacionais, caracterizando maior influência da política econômica sobre os fluxos especulativos do que sobre os de investimento direto.

Conforme análise de Ito (2000) sobre os diferentes efeitos do influxo de capital sobre as economias asiáticas e latino-americanas, existem fortes razões para a hipótese de que o grau de apreciação real da taxa de câmbio associada a um dado nível de IED tende a ser menor em magnitude do que em comparação com outros fluxos, em particular dos fluxos de portfólio e dos empréstimos bancários. Da mesma forma, Athucorala e Rajapatirana (2003) afirmam que o IED não é tão volátil quanto os investimentos de curto prazo, e que por esta razão seus efeitos sobre o câmbio são muito pequenos quando comparados aos outros tipos de investimentos estrangeiros. Por esta razão as pressões sobre o câmbio sentidas nas economias latino-americanas foram muito mais rigorosas do que nas asiáticas.

Ainda de acordo com dados do Banco Central do Brasil - Bacen, o influxo de investimento estrangeiro em carteira superou o IED nos anos de 2007, 2009 e 2010, sendo direcionado majoritariamente para renda variável, conforme Gráficos 1 e 2.

O saldo de investimento em carteira superior ao IED no ano de 2007 acompanha o citado aumento de liquidez internacional, e a recuperação rápida em 2009 e 2010 está relacionada ao relativamente amortecido efeito da crise financeira internacional sobre o país. Motivado pela defasagem de preço dos papéis após a deterioração da bolsa brasileira em 2008, o aumento do ingresso para a renda variável em 2009 foi o que mais se distanciou do ingresso para renda fixa na década. 


\section{GRÁFICO 1 - INVESTIMENTO ESTRANGEIRO EM CARTEIRA NO BRASIL (US\$ MILHÕES CORRENTES)}

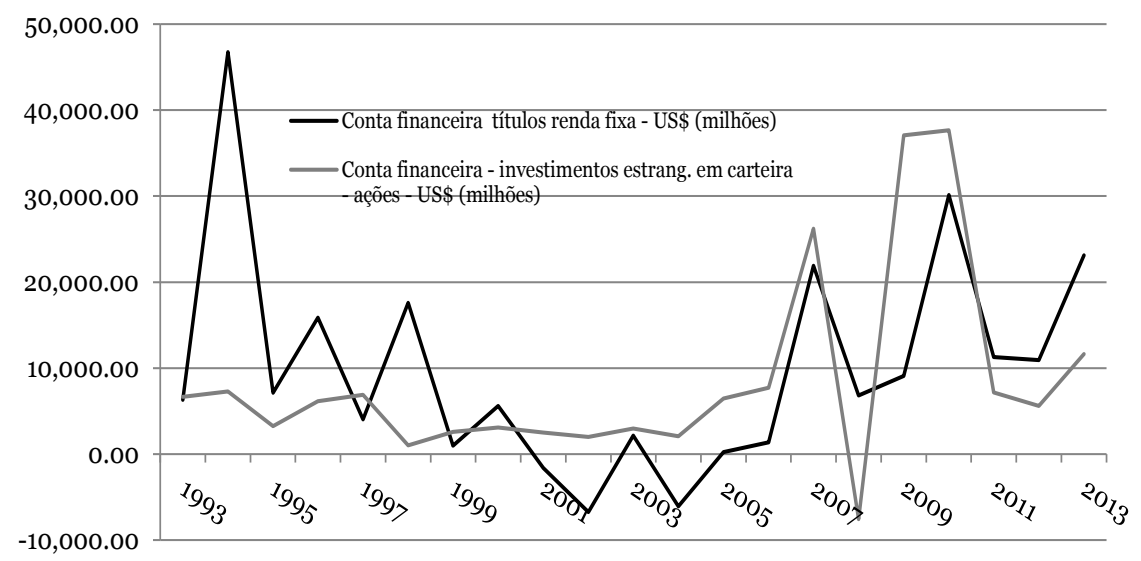

Fonte: Elaborado com base em dados do Banco Central do Brasil.

\section{GRÁFICO 2 - INVESTIMENTO ESTRANGEIRO NO BRASIL (US\$ MILHÕES CORRENTES)}

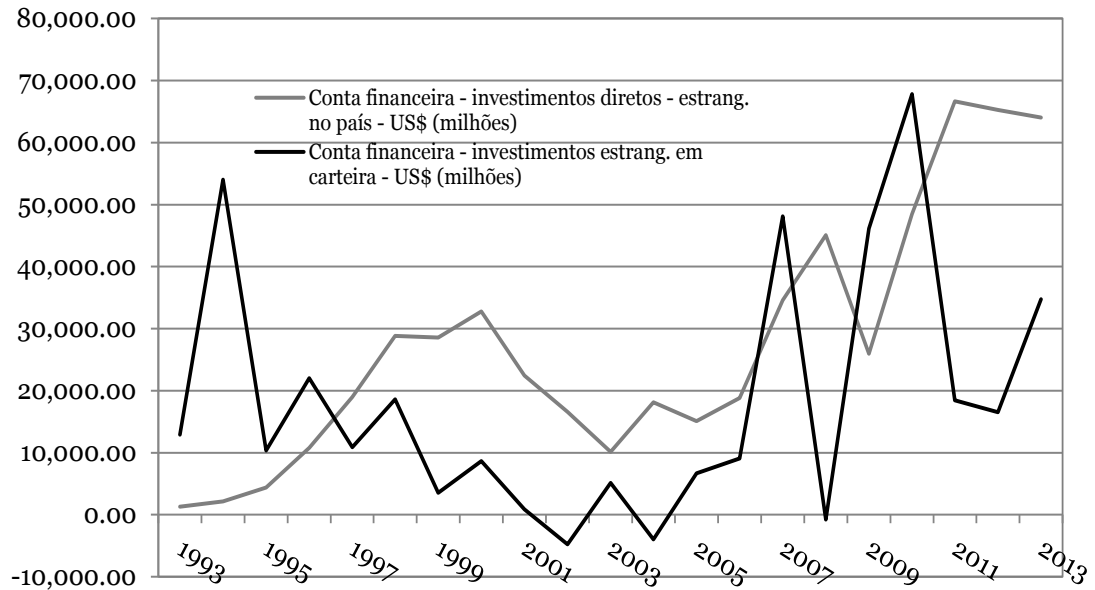

Fonte: Elaborado com base em dados do Banco Central do Brasil.

Uma sugestão para se aliviar a pressão em momentos de crise e evitar que a erosão das expectativas contamine o setor real da economia é dada por Carneiro (2003) no sentido de se dividir o mercado cambial. Desse modo seria possível, nos momentos de crise, criar mecanismos de controle de capital exclusivamente sobre o investimento em portfólio. De acordo com Soihet (2002), a relativa flexibilização da conta capital e financeira após a implementação do Plano Real e o diferencial de juros contribuíram significativamente para o aumento dos capitais na forma de portfólio direcionados ao Brasil. 
Callado e Amaral (2005) buscaram identificar fatores de atração e repulsão sobre o fluxo de capitais ao Brasil proveniente de investidores institucionais estrangeiros no período de 2003 a 2005. Verificaram que há predominância de fluxo para investimento em ações, e que a variável explicativa mais significativa do modelo é o spread médio pago pelos títulos brasileiros acima do $\mathrm{T}$ bond americano, relativo à classificação de risco país apurada pela agência Moody's.

Meurer (2005) confirmou estatisticamente a existência de uma relação complexa entre o comportamento dos investidores estrangeiros no mercado de ações brasileiro e o desempenho do Ibovespa, com a possibilidade de uma relação indireta através da liquidez gerada no mercado doméstico pelos investidores estrangeiros.

Através de estudos econométricos, Franzen et.al. (2009) apuraram que no período 1995-2005 "uma apreciação real da moeda brasileira em 1\% leva a uma saída de recursos correspondente a 6,6\% da participação estrangeira na capitalização do Ibovespa". Isso sugere que os investimentos estrangeiros em bolsa são influenciados por variações da taxa de câmbio contemporânea, que limitam sua exposição ao risco cambial assumindo uma operação de hedge cambial incompleto em suas operações na Bovespa.

\section{Metodologia}

Um modelo auto-regressivo de ordem p pode ser composto por um vetor de $\mathrm{n}$ variáveis endógenas $\mathrm{xt}$, conectadas por uma matriz A, conforme representado abaixo (Enders, 2010 e Bueno, 2008).

$$
x_{t}=A_{0}+A_{1} x_{t-1}+A_{2} x_{t-2}+\ldots+A_{p} x_{t-p}+G Z_{t}+e_{t}
$$

Onde xt é um vetor ( $\mathrm{n} \times 1$ ) contendo cada uma das $\mathrm{n}$ varáveis inseridas no VAR, Ao é um vetor ( $\mathrm{n} \times 1$ ) de termos de intercepto, Ai são matrizes ( $\mathrm{n} \times \mathrm{n}$ ) de parâmetros ou coeficientes e et é um vetor (n x 1) de perturbações aleatórias não correlacionadas e média zero. Ainda é possível acrescentar uma variável exógena, sendo G uma matriz de coeficientes ( $\mathrm{n}$ x g) e Zt um vetor (g $\mathrm{x}$ 1) de variáveis exógenas, que pode incluir variáveis determinísticas. Sendo assim, os modelos VAR expressam as relações lineares entre as variáveis endógenas, tanto contemporaneamente quanto por seus valores defasados, e podem também conter variáveis exógenas apenas como explicativas.

Dentre os estudos empíricos recentes que fizeram uso de procedimentos econométricos para avaliar os determinantes do fluxo de capitais, podemos destacar o trabalho realizado por Calvo, Leiderman e Reinhart (1993) analisando o peso dos fatores externos nos determinantes do influxo de capitais 
para a América Latina, através de um Vetor-Autoregressivo - VAR Estrutural. Edward (1998) utilizou VAR para testar a influência do influxo de capitais sobre a taxa de cambio. Cardoso e Vieira (2004) estudaram as mudanças na interação entre câmbio, inflação e juros no Brasil de 1994 a 2003 utilizando VAR. Pinheiro e Amin (2004) investigaram as interações entre fluxos de capitais, risco-país, dívida pública, taxa de juros e reservas no Brasil com modelo VAR. Pinto e Vieira (2008) analisaram o comportamento da taxa de câmbio e da inflação em países selecionados da América Latina, também com VAR.

Com base nos autores citados acima, a justificativa do uso da metodologia VAR se dá pelo fato de que os seus instrumentais estatísticos favorecem a análise proposta, uma vez que consideram a interação dinâmica das variáveis, sem que se assuma anteriormente quais das varáveis são explicadas e quais são explicativas. O modelo VAR é adequado devido à sua flexibilidade, uma vez que não impõe restrições relativas quanto à endogeneidade de uma ou mais variáveis nos modelos.

Após testes com diversas variáveis relacionadas, optou-se por utilizar apenas as mais significativas para manter o modelo parcimonioso, com não mais que quatro vetores, seguindo o modelo de VAR Estrutural de Sims em que todas as variáveis são tratadas simetricamente, evitando restrições de identificação (Enderes, 2010).

O modelo fundamenta-se nas seguintes variáveis: taxa de câmbio nominal em Real por Dólar, cotação ptax de fechamento, divulgada pelo Banco Central do Brasil - Bacen; Investimento Estrangeiro em Renda Variável discriminado entre fluxo de ingressos e de saídas, conforme divulgados pelo Bacen no Balanço de Pagamentos; Ibovespa nominal e em dólares divulgada pela BM\&F-Bovespa. Também foi considerado o Risco País apurado pelo JP Morgan, o EMBI+ Índex Brasil, como variável exógena. A base de dados tem periodicidade mensal, compreendendo o período de 1995 a 2012, em logaritmo natural.

Baseando-se na trajetória das variáveis e nas periodizações empregadas por Silva Jr. (2010) e Araújo et.al. (2010), optou-se por dividir o período em três fases, sendo a primeira de 1999 a 2002; a segunda de 2003 a 2007; e a terceira de 2008 a meados de 2012. Cada uma com suas especificidades de tendência e volatilidade bastante distintas.

Ao empregar um modelo único compreendendo todo o período, os estimadores não se mostraram adequados devido às quebras de tendências que a economia brasileira passou recentemente. Baseando-se nas periodizações empregadas por Silva Jr. (2010) e Araújo et.al. (2010), optou-se por dividir o período em três fases, sendo a primeira de 1999 a 2002; a segunda de 2003 a 2007; e a terceira de 2008 a meados de 2012. Cada uma com suas especificidades de tendência e volatilidade bastante distintas.

Verificou-se a estacionariedade das variáveis com os testes de raiz unitária Phillips-Perron (PP) e Kwiatkowski-Phillips-Schmidt-Shin (KPSS), 
disponíveis no software de econometria utilizado ${ }^{1}$ considerando-se as alternativas de existir ou não intercepto e inclinação. O teste PP faz uma correção não paramétrica para testar a existência de raiz unitária utilizando estimadores consistentes de variância, mesmo que haja variáveis defasadas dependentes e correlação serial nos erros (Phillips e Perron, 1988). O teste KPSS verifica a hipótese nula de que uma série seja estacionária em torno de uma tendência determinística (Kwiatkowski et.al., 1992).

Conforme Enders (2010) se faz necessário verificar se as variáveis não estacionárias individualmente se tornam estacionárias em conjunto. Segundo Maddala e Kim (2004), o Teste de cointegração de Johansen é o método mais utilizado para análises de cointegração, composto por dois testes estatísticos. O primeiro, chamado Teste Trace, verifica a hipótese de existir pelo menos $r$ vetores cointegrados. O segundo teste, chamado Maximum Eigenvalue, verifica a hipótese de que existam $\mathrm{r}+1$ vetores cointegrados.

Para a escolha do modelo quanto ao número de defasagens, Maddala e Kim (2004) afirmam que existem dois critérios geralmente utilizados, que refletem a proximidade do ajuste e o número de parâmetros estimados. São eles os Critérios de Akaike (Akaike Information Criterion - AIC) e Schwarz (Schwarz Bayesian Information Criterion - SC).

\section{Resultados}

\subsection{Período 1999-2002}

Os resultados obtidos para a fase de 1999 a 2002 encontram-se nas Tabelas 1.1 a 1.3. Os coeficientes extraídos do modelo VAR com as variáveis em log representam a variação percentual que ela irá sofrer devido à variação de $1 \%$ na variável explicativa, sendo consideradas elásticas no caso de coeficiente maior que 1 e inelásticas se o coeficiente ficar entre o e 1. Na relação fluxo-câmbio os coeficientes estatisticamente significativos apontam o câmbio como variável que explica ingressos e saídas, mas o contrário não ocorre. Esta relação só é significativa a $5 \%$ sobre o fluxo de ingressos, que apresenta relação inversa e inelástica, ou seja, uma valorização de $1 \%$ do dólar frente ao real provoca redução no fluxo de ingressos de IERV próxima de $0,8 \%$.

Não se verifica coeficientes significativos para a relação fluxo e bolsa em dólares, apenas as próprias variáveis com uma defasagem explicando o movimento seguinte a 5\% e 1\% de significância, em relação direta e inelástica. Já na tabela 1.3 há evidências de bolsa explicando câmbio a $5 \%$ de significância, em relação inversa e inelástica. Em outras palavras, uma valorização de 1\% do Ibovespa provoca uma queda de $0,16 \%$ na taxa real por dólar. Nesta análise incluiu-se

1 EViews 5.0 - Econometric Views, 1994-2004, Quantitative Micro Software, LLC. United States of America, Irvine, CA. 
também o risco país porque, de acordo com Callado e Amaral (2005), a variável é fundamental para explicar o comportamento dos investidores institucionais estrangeiros, uma vez que identificaram uma forte relação de causalidade desta sobre as decisões de investimento e expectativas dos agentes.

A maior parte destas relações é confirmada pelo teste de Causalidade de Granger, exposto na tabela 1.4. Novamente a taxa de câmbio é causa de ingressos e saídas a $5 \%$ no sentido de Granger. Já na relação fluxo-bolsa verifica-se uma relação de causalidade da bolsa sobre as saídas que não é significativa no VAR. No terceiro conjunto, confirma-se que bolsa causa câmbio a 1\%, e simultaneamente tem-se o oposto, bolsa explicada pelo câmbio a 10\%. Por fim, Risco-País causa taxa de câmbio a 10\% de significância no sentido de Granger.

TABELA 1.1 - SISTEMA VAR: SAÍDAS, INGRESSOS E CÂMBIO R\$/US\$ (1999 2002)

\begin{tabular}{lccc}
\hline & Saídas & Ingressos & Câmbio \\
\hline Saídas (-1) & $0,4504^{* * *}$ & $-0,0868$ & 0,0251 \\
& 0,1457 & 0,1943 & 0,0347 \\
Ingressos (-1) & 0,0509 & $0,332^{*}$ & $-0,0145$ \\
& 0,1371 & 0,1828 & 0,0326 \\
Câmbio (-1) & $-0,5297^{*}$ & $-0,8068^{* *}$ & $1,0047^{* * *}$ \\
& 0,2773 & 0,3698 & 0,0661 \\
C & $3,8722^{* * *}$ & $6,0051^{* * *}$ & $-0,0629$ \\
& 1,2211 & 1,6283 & 0,2908 \\
R2 Ajustado & 0,4597 & 0,3149 & 0,9052 \\
Schwarz Criterion & 0,6547 & 1,2302 & $-2,2151$ \\
$\mathrm{~N}$ & 47 & & \\
\hline
\end{tabular}

Fonte: Elaborado a partir dos resultados do modelo.

Obs.: Dados estatisticamente significativos a $10 \%^{*}, 5 \%^{* *}$ e $1 \%{ }^{* * *}$ 
TABELA 1.2 - SISTEMA VAR: BOLSA EM DÓLAR, INGRESSO E SAÍDAS (1999 - 2002)

\begin{tabular}{lccc}
\hline & Bolsa US\$ & Ingresso & Saídas \\
\hline Bolsa US\$ (-1) & $0,9104^{* * *}$ & 0,2970 & 0,2087 \\
& 0,0820 & 0,2120 & 0,1575 \\
Ingresso (-1) & 0,0382 & $0,3977^{* *}$ & 0,0858 \\
& 0,0733 & 0,1895 & 0,1408 \\
Saídas (-1) & $-0,0234$ & $-0,0080$ & $0,5014^{* * * *}$ \\
& 0,0756 & 0,1954 & 0,1452 \\
C & 0,6635 & 1,7934 & 1,0372 \\
& 0,5911 & 1,5277 & 1,1349 \\
R2 Ajustado & 0,8209 & 0,2723 & 0,4368 \\
Schwarz Criterion & $-0,6085$ & 1,2906 & 0,6961 \\
$\mathrm{~N}$ & 47 & & \\
\hline
\end{tabular}

Fonte: Elaborado a partir dos resultados do modelo.

Obs.: Dados estatisticamente significativos a $10 \% *, 5 \% *$ e $1 \%{ }^{* * *}$

TABELA 1.3 - SISTEMA VAR: BOLSA E CÂMBIO R \$/US\$ COM RISCO PAÍS EXÓGENO EM $1^{\text {a }}$ DIFERENÇA (2003-2007)

\begin{tabular}{lrr}
\hline & Bolsa & Câmbio \\
\hline Bolsa (-1) & 0,0096 & $-0,1582^{* *}$ \\
Câmbio (-1) & 0,1333 & 0,0773 \\
& $-0,0059$ & $-0,1888^{*}$ \\
C & 0,1957 & 0,1135 \\
& 0,0056 & $0,0147^{* * *}$ \\
Embi+ & 0,0097 & 0,00563 \\
& $-0,4650^{* * *}$ & $0,3206^{* * *}$ \\
R2 Ajustado & 0,0576 & 0,0334 \\
Schwarz Criterion & 0,6147 & 0,7312 \\
$\mathrm{~N}$ & $-2,4721$ & $-3,5623$ \\
\hline
\end{tabular}

Fonte: Elaborado a partir dos resultados do modelo.

Obs.: Dados estatisticamente significativos a $10 \% *$, $5 \%^{* *}$ e $1 \%$ *** 
TABELA 1.4 - TESTE DE CAUSALIDADE DE GRANGER: SAÍDAS, INGRESSOS E CÂMBIO R\$/US\$ (1999 - 2002)

\begin{tabular}{|c|c|c|c|c|}
\hline \multicolumn{2}{|c|}{ Hipótese nula de não causalidade } & \multirow{2}{*}{$\begin{array}{r}\text { Obs } \\
47\end{array}$} & \multirow{2}{*}{$\begin{array}{r}\text { F-Statistic } \\
2,106\end{array}$} & \multirow{2}{*}{$\begin{array}{r}\text { Probability } \\
0,154\end{array}$} \\
\hline Ingressos & Saídas & & & \\
\hline Saídas & Ingressos & & 0,003 & 0,958 \\
\hline Câmbio & Saídas & 47 & 5,858 & $0,0197^{* * *}$ \\
\hline Saídas & Câmbio & & 0,350 & 0,557 \\
\hline Câmbio & Ingressos & 47 & 4,647 & $0,0366^{* *}$ \\
\hline Ingressos & Câmbio & & 0,021 & 0,885 \\
\hline Ingressos & Bolsa US\$ & 47 & 0,181 & 0,673 \\
\hline Bolsa US\$ & Ingressos & & 2,009 & 0,163 \\
\hline Saídas & Bolsa US\$ & 47 & 0,002 & 0,966 \\
\hline Bolsa US\$ & Saídas & & 3,578 & $0,0651^{*}$ \\
\hline Saídas & Ingressos & 47 & 0,003 & 0,958 \\
\hline Ingressos & Saídas & & 2,106 & 0,154 \\
\hline Câmbio & Bolsa & 46 & 3,4828 & $0,0688^{*}$ \\
\hline Bolsa & Câmbio & & 8,8331 & $0,0048^{* * *}$ \\
\hline Embi+ & Bolsa & 46 & 2,0241 & 0,1620 \\
\hline Bolsa & Embi+ & & 2,8150 & 0,1006 \\
\hline Embi+ & Câmbio & 46 & 3,7427 & $0,0596^{*}$ \\
\hline Câmbio & Embi+ & & 2,5316 & 0,1189 \\
\hline
\end{tabular}

Fonte: Elaborado a partir dos resultados do modelo.

Obs.: Dados estatisticamente significativos a $10 \%^{*}, 5^{* *}$ e $1 \%^{* * *}$

Analisando comparativamente as funções de impulso resposta deste sistema VAR, a Figura 2 traz os resultados para o primeiro período. Saídas e entradas de IERV respondem negativamente a uma variação na taxa de câmbio, e após o choque a taxa não converge de volta para o eixo. Na Figura 3 a função impulso resposta apresenta resultado significativo para um choque na variável bolsa sobre as de fluxo ingresso e saída de ordem direta, e após alguns períodos estas tendem a voltar para o eixo. A Figura 4 apresenta a variável câmbio respondendo negativamente a um choque na bolsa, assim como no VAR e no teste de causalidade de Granger. 
FIGURA 2 - FUNÇÕES IMPULSO-RESPOSTA DO SISTEMA VAR 1.1: SAÍDAS, INGRESSOS E CÂMBIO R\$/US\$ (1999 - 2002).

Res pons e to Choles ky One S.D. Innovations \pm 2 S.E.
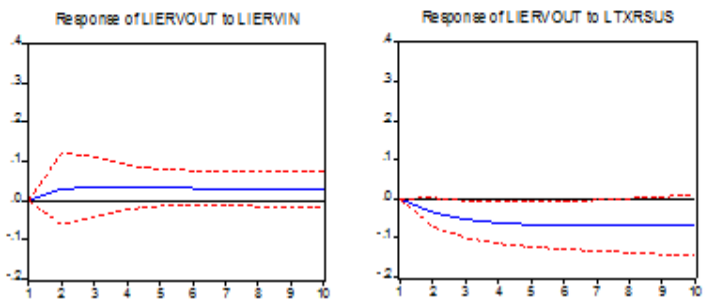

Responæ of LERVIN to LERVOUT
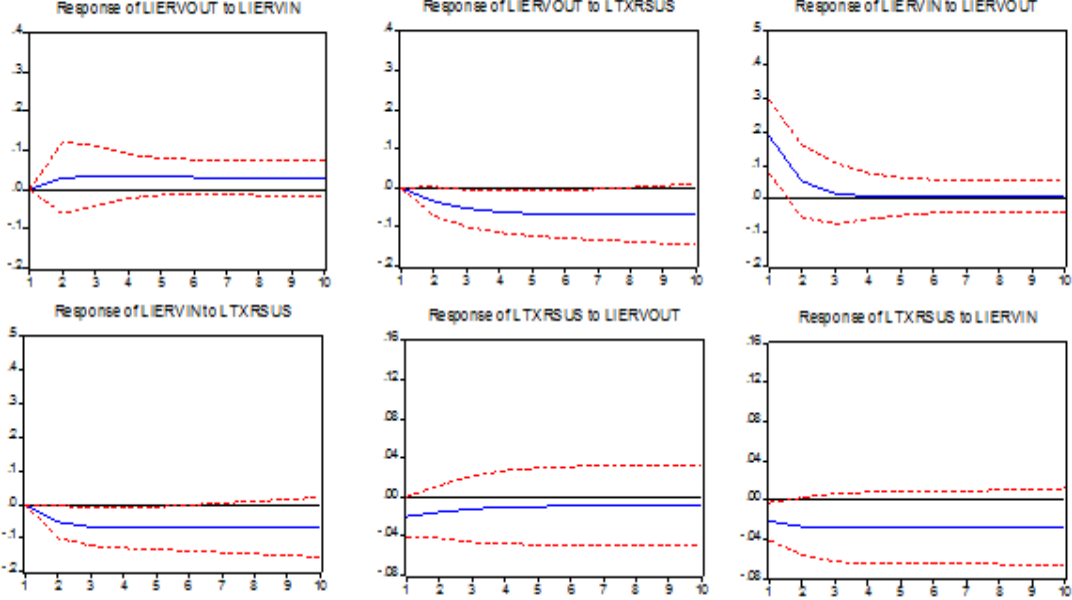

Fonte: Elaboração própria com base no modelo.

FIGURA 3 - IMPULSO RESPOSTA DO SISTEMA VAR 1.2: BOLSA EM DÓLAR, INGRESSOS E SAÍDAS (1999 - 2002)

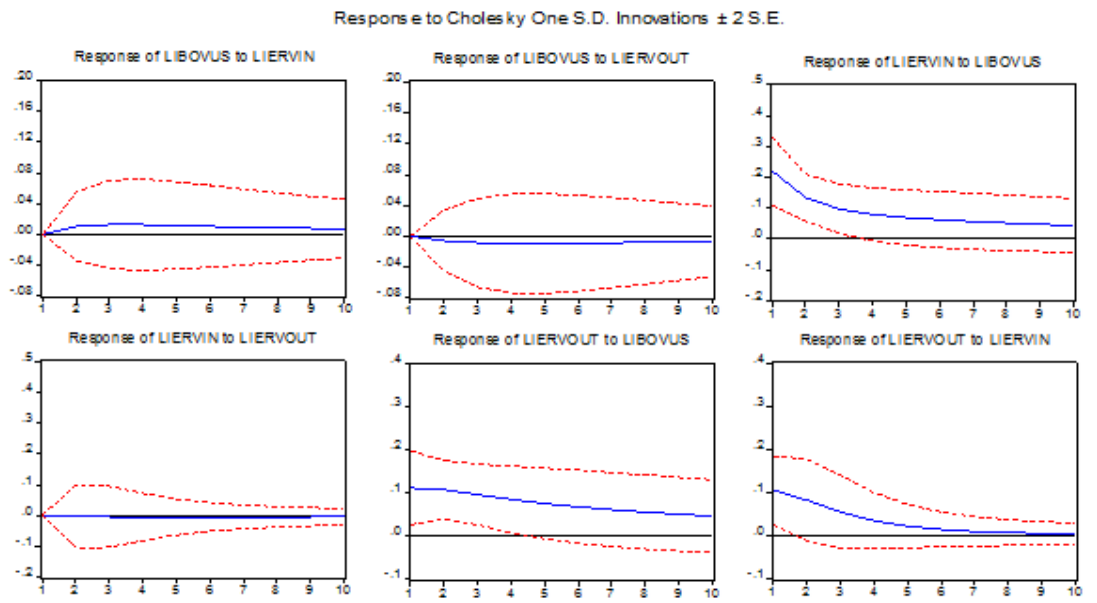

Fonte: Elaboração própria com base no modelo. 
FIGURA 4 - IMPULSO RESPOSTA DO SISTEMA VAR 1.3: BOLSA E CÂMBIO R \$ / US\$ COM RISCO PAÍS EXÓGENO EM 1a DIFERENÇA (1999-2002)

Response to Cholesky One S.D. Innovations \pm 2 S.E.

Response of DLIBOV to DLTXRSUS

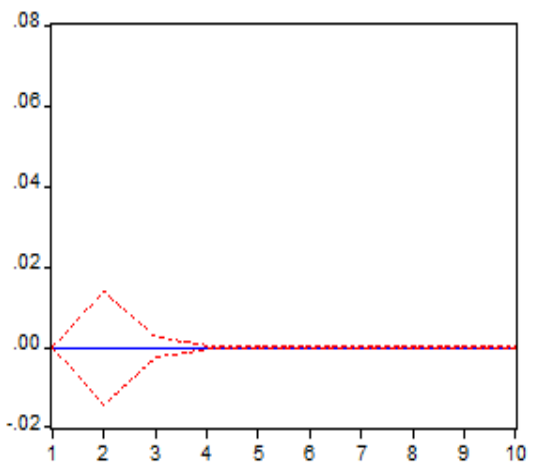

Response of DLTXRSUS to DLIBOV

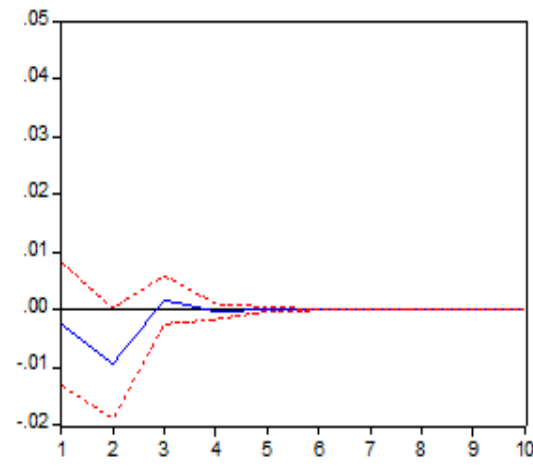

Fonte: Elaboração própria com base no modelo.

\subsection{Período $2003-2007$}

No período seguinte, as Tabelas 2.1 a 2.3 expõem os coeficientes obtidos no VAR e a Tabela 2.4 o teste de Causalidade de Granger. De 2003 a 2007 temos novamente câmbio causando fluxo a 1\% de significância, porém agora com coeficientes elásticos, e o fluxo de saídas causando a taxa de câmbio a $1 \%$, relação confirmada no teste de causalidade. Este coeficiente em relação inversa com o câmbio significa que a saída de IERV está provocando queda na taxa real por dólar, o que não pode ser analisado isoladamente uma vez que o período teve apenas apreciação do real.

No segundo conjunto os coeficientes mostraram-se significativos para bolsa em dólares causando fluxo, tanto pelo VAR quanto por Granger, em nível de 1\% de significância. Assim como na relação câmbio-fluxo, os coeficientes para uma variação de 1\% da bolsa sobre ingresso e saída são igualmente elásticos, impactando em 1,3\% e 1,15\% respectivamente. O teste para bolsa nominal e câmbio mostra ambos sendo apenas explicados pelo risco país no modelo VAR, mas o de Causalidade de Granger não apresenta dados significativos para nenhuma relação. 
TABELA 2.1 - SISTEMA VAR: SAÍDAS, INGRESSO E CÂMBIO R\$/US\$ (2003 2007)

\begin{tabular}{lrrr}
\hline & \multicolumn{1}{c}{ Saídas } & \multicolumn{1}{c}{ Ingresso } & \multicolumn{1}{c}{ Câmbio } \\
\hline Saídas (-1) & 0,1118 & $-0,0226$ & $-0,065^{* * *}$ \\
& 0,1905 & 0,2159 & 0,0212 \\
Ingresso (-1) & 0,2260 & 0,1980 & 0,0324 \\
& 0,1807 & 0,2049 & 0,0201 \\
Câmbio (-1) & $-2,9234^{* * *}$ & $-3,6713^{* * * *}$ & $0,8295^{* * *}$ \\
& 0,5761 & 0,6530 & 0,0641 \\
C & $7,7833^{* * *}$ & $9,9184^{* * *}$ & $0,3957^{* *}$ \\
& 1,4663 & 1,6621 & 0,1631 \\
R2 Ajustado & 0,8662 & 0,8357 & 0,9627 \\
Schwarz Criterion & 0,7228 & 0,9734 & $-3,6696$ \\
N & 59,0000 & & \\
\hline
\end{tabular}

Fonte: Elaborado a partir dos resultados do modelo.

Obs.: Dados estatisticamente significativos a $10 \%{ }^{*}, 5 \% * *$ e $1 \%{ }^{* * *}$

TABELA 2.2 - SISTEMA VAR: BOLSA EM DÓLAR, INGRESSO E SAÍDAS (2003 - 2007)

\begin{tabular}{lrrr}
\hline & \multicolumn{1}{c}{ Bolsa US\$ } & \multicolumn{1}{c}{ Ingresso } & \multicolumn{1}{c}{ Saídas } \\
\hline Bolsa US\$ (-1) & $0,9207^{* * *}$ & $1,3096^{* * *}$ & $1,1520^{* * *}$ \\
& 0,0490 & 0,2008 & 0,1666 \\
Ingresso (-1) & $-0,0288$ & 0,1748 & 0,1823 \\
& 0,0471 & 0,1929 & 0,1601 \\
Saídas (-1) & 0,0790 & $-0,2146$ & $-0,0946$ \\
& 0,0520 & 0,2130 & 0,1767 \\
C & $0,3976^{* *}$ & $-3,9515^{* * *}$ & $-3,6663^{* * *}$ \\
& 0,2078 & 0,8510 & 0,7061 \\
R2 Ajustado & 0,9836 & 0,8541 & 0,8949 \\
Schwarz Crite- & $-1,9654$ & 0,8546 & 0,4812 \\
rion & & & \\
$\mathrm{N}$ & 59,0000 & & \\
\hline
\end{tabular}

Fonte: Elaborado a partir dos resultados do modelo.

Obs.: Dados estatisticamente significativos a 10\%*, $5 \%^{* *}$ e $1 \% * * *$ 
TABELA 2.3 - SISTEMA VAR: BOLSA E CÂMBIO R \$/US\$ COM RISCO PAÍS EXÓGENO EM $1^{\text {a }}$ DIFERENÇA (2003-2007)

\begin{tabular}{lrr}
\hline & Bolsa & Câmbio \\
\hline Bolsa (-1) & 0,0822 & $-0,0206$ \\
Câmbio (-1) & 0,1038 & 0,0780 \\
& 0,1585 & $-0,1732$ \\
C & 0,1651 & 0,1241 \\
& $0,0204^{* * *}$ & $-0,0084^{*}$ \\
Embi+ & 0,0065 & 0,0049 \\
& $-0,3628^{* * *}$ & $0,1758^{* * *}$ \\
R2 Ajustado & 0,0516 & 0,0388 \\
Schwarz Criterion & 0,4678 & 0,2741 \\
N & $-3,2540$ & $-3,8245$ \\
\hline
\end{tabular}

Fonte: Elaborado a partir dos resultados do modelo.

Obs.: Dados estatisticamente significativos a 10\%*, $5 \%$ ** e $1 \% * * *$

Pela função impulso-resposta na Figura 5 (em anexo), confirma-se que um choque sobre a taxa de câmbio causa uma variação no fluxo de ordem inversa e elástica, ou seja, a valorização do real em 1\% causa um aumento de ingresso e saída maiores que 1\%. Simultaneamente, um choque nas saídas de IERV provoca variação negativa e elástica sobre o câmbio. A Figura 6 expõe o efeito que um choque sobre a bolsa exerce no fluxo, de relação direta atingindo um pico no segundo período mais que proporcional. E na Figura 7 os efeitos não são significativos. 
MATOS, M. S.; MORAES, G. I. Investimento Estrangeiro em Renda Variável....

TABELA 2.4 - TESTE DE CAUSALIDADE DE GRANGER: SAÍDAS, INGRESSOS E CÂMBIO R\$/US\$ (2003 - 2007)

\begin{tabular}{|c|c|c|c|c|}
\hline \multicolumn{2}{|c|}{ Hipótese nula de não causalidade } & \multirow{2}{*}{$\begin{array}{r}\text { Obs } \\
59\end{array}$} & \multirow{2}{*}{$\begin{array}{r}\text { F-Statistic } \\
4,5342\end{array}$} & \multirow{2}{*}{$\begin{array}{r}\text { Probability } \\
0,0376^{* * *}\end{array}$} \\
\hline Ingressos & Saídas & & & \\
\hline Saídas & Ingressos & & 2,9157 & $0,0932^{*}$ \\
\hline Câmbio & Saídas & 59 & 30,4182 & $0,000^{* * *}$ \\
\hline Saídas & Câmbio & & 8,4598 & $0,005^{* * *}$ \\
\hline Câmbio & Ingressos & 59 & 36,7550 & $0,000^{* * *}$ \\
\hline Ingressos & Câmbio & & 1,4186 & 0,2387 \\
\hline Ingressos & Bolsa US\$ & 59 & 0,462 & 0,500 \\
\hline Bolsa US\$ & Ingressos & & 46,591 & $0,000^{* * *}$ \\
\hline Saídas & Bolsa US\$ & 59 & 2,436 & 0,124 \\
\hline Bolsa US\$ & Saídas & & 54,562 & $0,000^{* * *}$ \\
\hline Saídas & Ingressos & 59 & 2,916 & $0,093^{*}$ \\
\hline Ingressos & Saídas & & 4,534 & $0,038^{* *}$ \\
\hline Câmbio & Bolsa & 58 & 1,7715 & 0,1887 \\
\hline Bolsa & Câmbio & & 0,1921 & 0,6629 \\
\hline Embi+ & Bolsa & 58 & 0,0445 & 0,8337 \\
\hline Bolsa & Embi+ & & 0,2947 & 0,5894 \\
\hline Embi+ & Câmbio & 58 & 1,6031 & 0,2108 \\
\hline Câmbio & Embi+ & & 1,9216 & 0,1713 \\
\hline
\end{tabular}

Fonte: Elaborado a partir dos resultados do modelo.

Obs.: Dados estatisticamente significativos a $10 \%^{*}, 5 \%^{* *}$ e $1 \%{ }^{* * *}$ 
FIGURA 5 - IMPULSO RESPOSTA DO SISTEMA VAR 2.1: SAÍDAS, INGRESSOS E CÂMBIO R\$/US\$ (2003 - 2007).

Response to Cholesky One S.D. Innovations \pm 2 S. E.

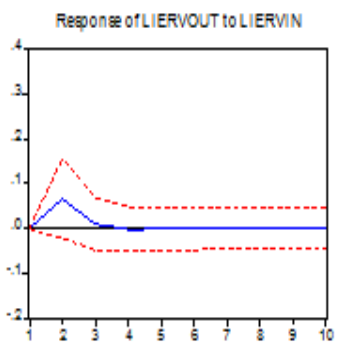

FesPong OFLERVOUT DOLTXFSUS
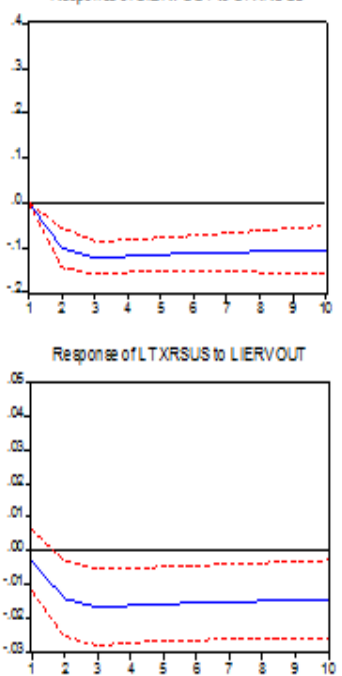

Fesoone of LERVNNOL ERVOUT

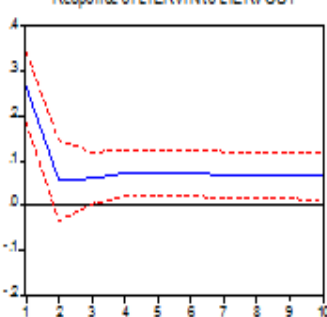

Respong ofLTXFSUS to LERVIN

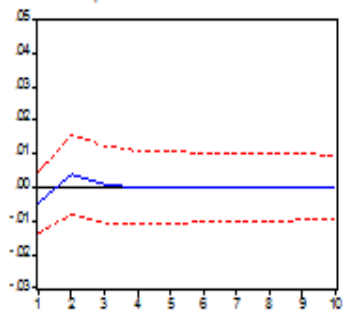

Fonte: Elaboração própria com base no modelo.

FIGURA 6 - IMPULSO RESPOSTA DO SISTEMA VAR 2.2: BOLSA EM DÓLAR, INGRESSOS E SAÍDAS (2003 - 2007)

Response to CholeskyOne S.D. Innovations \pm 2 S.E.
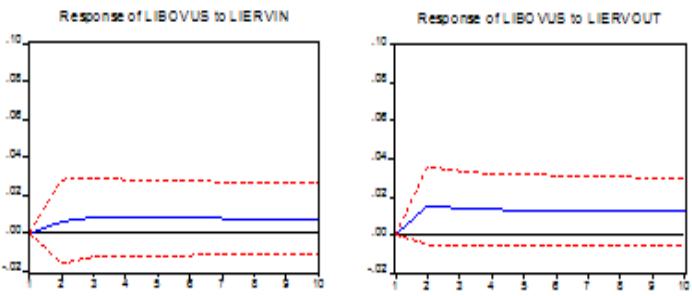

Resoonse otLIERVIN to UBOOWU
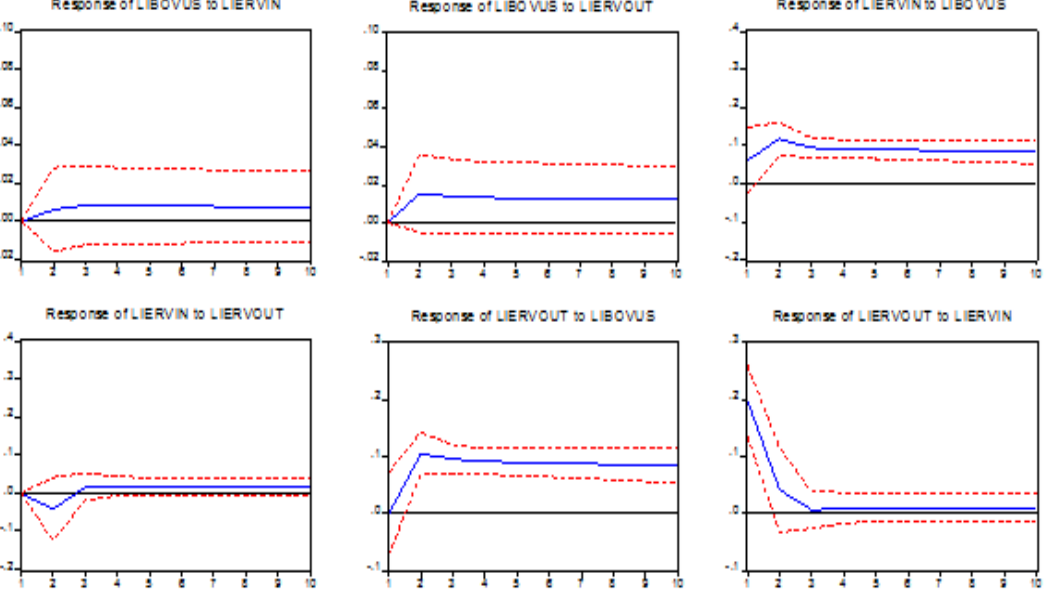

Fonte: Elaboração própria com base no modelo. 
FIGURA 7 - IMPULSO RESPOSTA DO SISTEMA VAR 2.3: BOLSA E CÂMBIO R\$/ US\$ COM RISCO PAÍS EXÓGENO EM 1ª DIFERENÇA (2003-2007).

Response to Cholesky One S.D. Innovations \pm 2 S.E.

Response of DLIBOV to DLTXRSUS

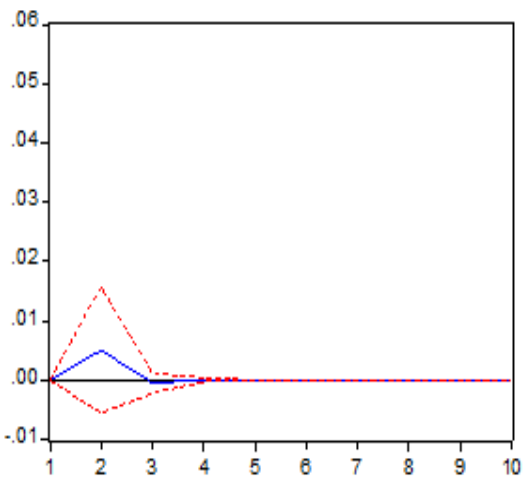

Response of DLTXRSUS to DLIBOV

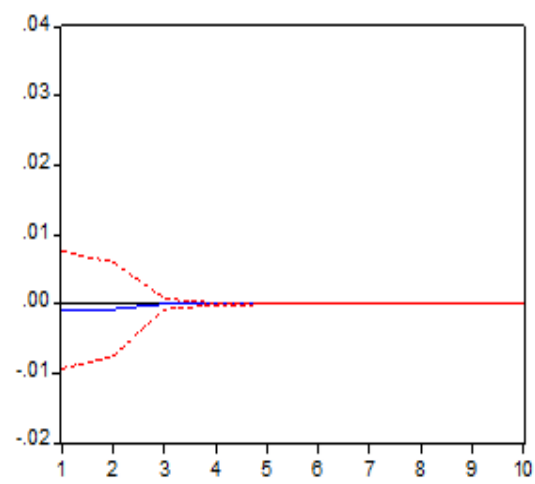

Fonte: Elaboração própria com base no modelo.

\subsection{Período 2008-2012}

O período 2008-2012 é exposto nas Tabelas 3.1 a 3.3, diferenciando-se dos anteriores pela inclusão do Risco País em todos os conjuntos VAR. No primeiro conjunto a variável taxa de câmbio explica o fluxo de saídas, porém significante apenas a 10\%. O risco-país influencia os ingressos e a taxa de câmbio a $5 \%$ e $1 \%$ de significância, respectivamente. O coeficiente para ingressos é inelástico e negativo, e o da taxa de câmbio é inelástico e positivo. Pelo teste de Causalidade de Granger, verifica-se que tanto a taxa de câmbio quanto o risco-país explicam o fluxo de IERV.

No segundo conjunto verifica-se o fluxo de ingressos influenciando bolsa em dólares a $5 \%$ de significância, em relação direta e inelástica. No teste de Causalidade de Granger esta relação não tem significância estatística, mas o fluxo de saídas surge como causa da bolsa em dólares a $5 \%$ de significância. No terceiro sistema VAR não se verifica coeficientes significativos, apenas no teste de Causalidade onde bolsa explica taxa de câmbio a 5\% no sentido de Granger. 
TABELA 3.1 - SISTEMA VAR: SAÍDAS, INGRESSO E CÂMBIO R \$/US \$ COM RISCO PAÍS EXÓGENO (2008 - 2012) EM 1a DIFERENÇA

\begin{tabular}{lrrr}
\hline & \multicolumn{1}{c}{ Saídas } & \multicolumn{1}{c}{ Ingresso } & \multicolumn{1}{c}{ Câmbio } \\
\hline Saídas (-1) & $-0,5468^{* * *}$ & $-0,0484$ & $-0,0101$ \\
Ingresso (-1) & 0,1807 & 0,1958 & 0,0229 \\
& 0,0168 & $-0,4074^{* *}$ & $-0,0074$ \\
Câmbio (-1) & 0,1805 & 0,1955 & 0,0228 \\
& $-1,7989^{*}$ & $-1,5035$ & 0,0133 \\
C & 0,9446 & $-1,0232$ & 0,1195 \\
& $-0,0092$ & $-0,0093$ & 0,0041 \\
Embi+ & 0,0440 & 0,0477 & 0,0056 \\
& $-0,1424$ & $-0,7039^{* *}$ & $0,2684^{* * *}$ \\
R2 Ajustado & 0,3288 & 0,3562 & 0,0416 \\
Schwarz Criterion & 0,2423 & 0,2122 & 0,4499 \\
N & 0,7862 & 0,9462 & $-3,3484$ \\
\hline
\end{tabular}

Fonte: Elaborado a partir dos resultados do modelo.

Obs.: Dados estatisticamente significativos a 10\%*, 5\%** e $1 \%$ ***

TABELA 3.2 - SISTEMA VAR: BOLSA EM DÓLAR, INGRESSO E SAÍDAS COM RISCO PAÍS EXÓGENO (2008 - 2012)

\begin{tabular}{lccc}
\hline & Bolsa US $\$$ & Ingresso & Saídas \\
\hline Bolsa US\$ (-1) & $0,3774^{* * *}$ & $-0,2714$ & $-0,0419$ \\
& 0,0958 & 0,3975 & 0,3823 \\
Ingresso (-1) & $0,1156^{* *}$ & $0,5439^{* *}$ & 0,2350 \\
Saídas (-1) & 0,05609 & 0,2327 & 0,2238 \\
& $-0,0698$ & 0,2233 & $0,5676^{* * *}$ \\
C & 0,0534 & 0,2216 & 0,2131 \\
& $9,1610^{* * *}$ & 7,5500 & 2,5342 \\
Embi+ & $-1,3482$ & $-5,5942$ & $-5,3804$ \\
& $-0,5725^{* * *}$ & $-0,4642$ & $-0,0634$ \\
R2 Ajustado & 0,0971 & 0,4030 & 0,3876 \\
Schwarz Criterion & 0,9126 & 0,4567 & 0,5511 \\
$\mathrm{~N}$ & $-1,8144$ & 1,0315 & 0,9535 \\
\hline
\end{tabular}

Fonte: Elaborado a partir dos resultados do modelo.

Obs.: Dados estatisticamente significativos a $10 \% *, 5 \%{ }^{* *}$ e $1 \%{ }^{* * *}$ 
TABELA 3.3 - SISTEMA VAR: BOLSA E CÂMBIO R\$/US \$ COM RISCO PAÍS EXÓGENO EM 1 a DIFERENÇA (2008-2012)

\begin{tabular}{lrr}
\hline & Bolsa & Câmbio \\
\hline Bolsa (-1) & 0,0195 & $-0,1229$ \\
Câmbio (-1) & 0,1351 & 0,1047 \\
& $-0,0435$ & $-0,0578$ \\
$\mathrm{C}$ & 0,1853 & 0,1435 \\
& $-0,0034$ & 0,0043 \\
Embi+ & 0,0071 & 0,0055 \\
& $-0,4028^{* * *}$ & $0,2451^{* * *}$ \\
R2 Ajustado & 0,0533 & 0,0412 \\
Schwarz Criterion & 0,5582 & 0,4669 \\
$\mathrm{~N}$ & $-2,9249$ & $-3,4361$ \\
\hline
\end{tabular}

Fonte: Elaborado a partir dos resultados do modelo.

Obs.: Dados estatisticamente significativos a 10\%* $5 \%$ ** e $1 \%$ *** 
TABELA 3.4 - TESTE DE CAUSALIDADE DE GRANGER: SAÍDAS, INGRESSOS, CÂMBIO R\$/US\$ E RISCO PAÍS (2008 - 2012) EM 1a DIFERENÇA

\begin{tabular}{|c|c|c|c|c|}
\hline \multicolumn{2}{|c|}{ Hipótese nula de não causalidade } & \multirow{2}{*}{$\frac{\mathrm{Obs}}{50}$} & \multirow{2}{*}{$\frac{\text { F-Statistic }}{0,6661}$} & \multirow{2}{*}{$\frac{\text { Probability }}{0,4186}$} \\
\hline Ingressos & Saídas & & & \\
\hline Saídas & Ingressos & & 0,3837 & 0,5386 \\
\hline Câmbio & Saídas & 50 & 5,0314 & $0,0296 * *$ \\
\hline Saídas & Câmbio & & 0,2614 & 0,6116 \\
\hline Embi+ & Saídas & 50 & 5,1131 & $0,0284^{* *}$ \\
\hline Saídas & Embi+ & & 2,4755 & 0,1223 \\
\hline Câmbio & Ingressos & 50 & 3,6395 & $0,0625^{*}$ \\
\hline Ingressos & Câmbio & & 0,1453 & 0,7048 \\
\hline Embi+ & Ingressos & 50 & 4,6513 & $0,0362^{* *}$ \\
\hline Ingressos & Embi+ & & 1,5610 & 0,2177 \\
\hline Embi+ & Câmbio & 50 & 0,2773 & 0,6009 \\
\hline Câmbio & Embi+ & & 0,3834 & 0,5388 \\
\hline Ingressos & Bolsa US\$ & 51 & 1,7753 & 0,1890 \\
\hline Bolsa US\$ & Ingressos & & 0,1285 & 0,7215 \\
\hline Saídas & Bolsa US\$ & 51 & 4,9208 & $0,0313^{* *}$ \\
\hline Bolsa US\$ & Saídas & & 0,3892 & 0,5357 \\
\hline Embi+ & Bolsa US\$ & 51 & 0,2481 & 0,6207 \\
\hline Bolsa US\$ & Embi+ & & 2,2276 & 0,1421 \\
\hline Saídas & Ingressos & 51 & 0,2589 & 0,6132 \\
\hline Ingressos & Saídas & & 1,5273 & 0,2225 \\
\hline Embi+ & Ingressos & 51 & 0,0564 & 0,8133 \\
\hline Ingressos & Embi+ & & 2,6126 & 0,1126 \\
\hline Embi+ & Saídas & 51 & 0,0400 & 0,8424 \\
\hline Saídas & Embi+ & & 5,9760 & $0,01822^{* *}$ \\
\hline Câmbio & Bolsa & 50 & 0,1049 & 0,7475 \\
\hline Bolsa & Câmbio & & 4,9450 & $0,0310^{* *}$ \\
\hline Embi+ & Bolsa & 50 & 0,4855 & 0,4894 \\
\hline Bolsa & Embi+ & & 5,6508 & $0,0216^{* *}$ \\
\hline Embi+ & Câmbio & 50 & 0,2773 & 0,6009 \\
\hline Câmbio & Embi+ & & 0,3834 & 0,5388 \\
\hline
\end{tabular}

Fonte: Cálculos da autora baseados em dados do Banco Central do Brasil e IPEADATA.

Obs.: Dados estatisticamente significativos a $10 \% *, 5 \%^{* *}$ e $1 \%{ }^{* * *}$

Partindo para as funções impulso-resposta, este último período está representado na Figura 8 onde verifica-se uma resposta da taxa de câmbio para um choque no fluxo de saída de IERV, que não foi significativa nos testes 
anteriores. A Figura 9 traz o fluxo de entrada respondendo a um choque na bolsa, significativo apenas no primeiro período e depois retornando para o eixo. E na Figura 10 se conclui as análises de impulso resposta com a relação câmbio-bolsa, que apresenta uma resposta mais que proporcional da taxa de câmbio após um choque no Ibovespa.

FIGURA 8 - IMPULSO RESPOSTA DO SISTEMA VAR 3.1: SAÍDAS, INGRESSOS E CÂMBIO R\$/US\$ COM RISCO PAÍS EXÓGENO EM $1^{\text {a }}$ DIFERENÇA (20082012).

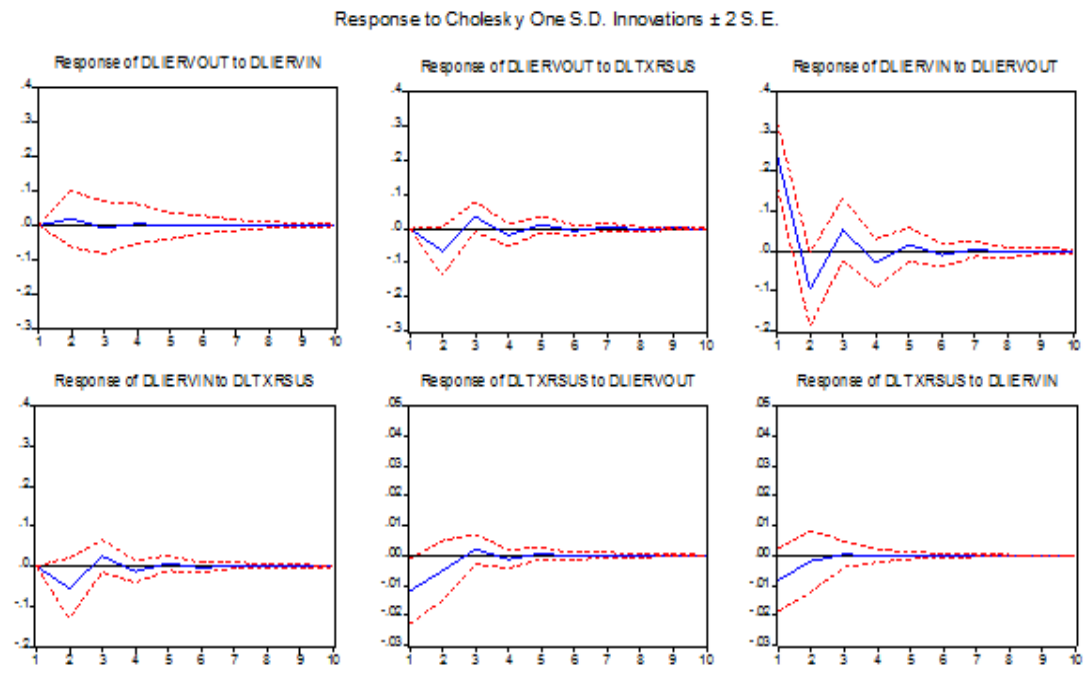

Fonte: Elaboração própria com base no modelo. 
FIGURA 9 - IMPULSO RESPOSTA DO SISTEMA VAR 3.2: BOLSA EM DÓLAR, INGRESSOS E SAÍDAS COM RISCO PAÍS EXÓGENO (2008 - 2012)

Res ponse to Cholesky One S.D. Innovations \pm 2 S.E.
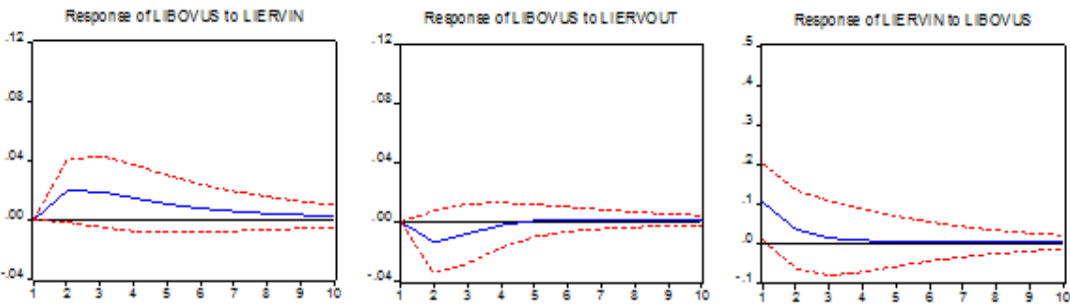

FeæO ONGe of LERVIN to LIERVOU
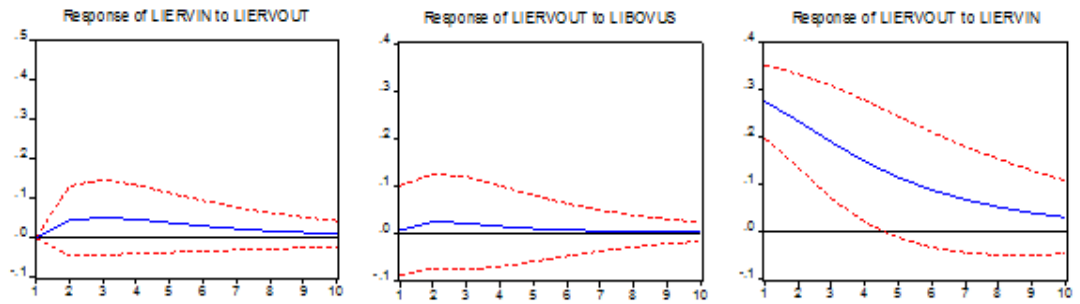

Fonte: Elaboração própria com base no modelo.

FIGURA 10 - IMPULSO RESPOSTA DO SISTEMA VAR 3.3: BOLSA E CÂMBIO R\$/ US\$ COM RISCO PAÍS EXÓGENO EM 1ª DIFERENÇA (2008-2012).

Response to Cholesky One S.D. Innovations \pm 2 S.E.
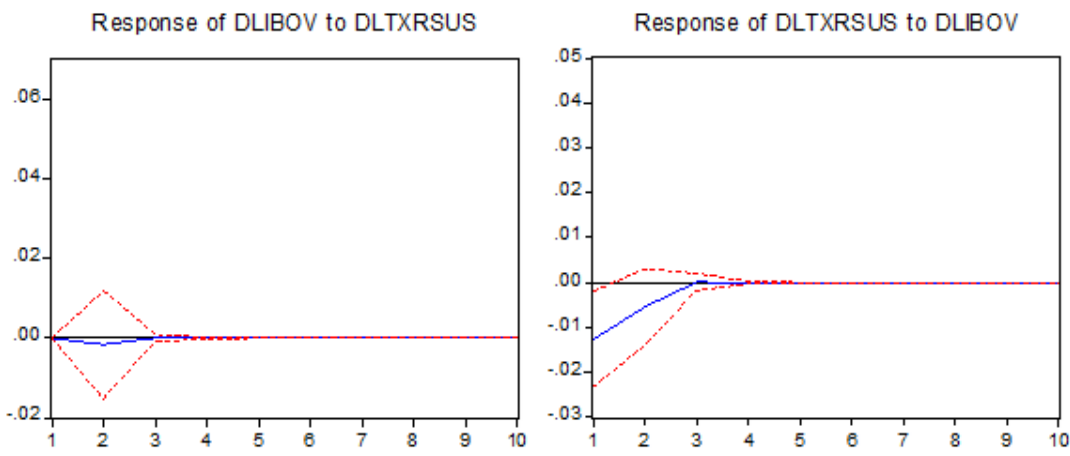

Fonte: Elaboração própria com base no modelo.

Para uma visualização mais concisa, as saídas foram reunidas nas tabelas 4.1 a 4.4 com base nos coeficientes obtidos no modelo VAR e na relação de Causalidade de Granger, focando na variável como explicativa das demais. A tabela 4.1 expõe as variáveis que são influenciadas pelo risco-país, eviden- 
ciando seu peso sobre câmbio e bolsa em todos os períodos. As saídas para câmbio evidenciam uma relação positiva entre aumento do risco-país e da cotação do dólar frente ao real de forma inelástica, ou seja, variação média de $0,25 \%$ para $1 \%$ de aumento do Embi+. Os coeficientes do risco país sobre a variação do Ibovespa em sinal negativo significam que o aumento de $1 \%$ do Embi+ provocará queda média de 0,4\% na bolsa, relação inversa e inelástica.

TABELA 4.1 - RESUMO DO EMBI+ COMO EXPLICATIVA

\begin{tabular}{lccc}
\hline & $1999-2002$ & $2003^{-2007}$ & $2008-2012$ \\
\hline Saídas & $\mathrm{NT}$ & $\mathrm{NT}$ & $\mathrm{NS}$ \\
Ingresso & $\mathrm{NT}$ & $\mathrm{NT}$ & $-0,7039^{* *}$ \\
Câmbio & $0,3206^{* * *}$ & $0,1758^{* * *}$ & $0,2684^{* * *}$ \\
Bolsa US\$ & $\mathrm{NT}$ & $\mathrm{NT}$ & $-0,5725^{* * *}$ \\
Bolsa Nominal & $-0,4650^{* * *}$ & $-0,3628^{* * *}$ & $-0,4028^{* * *}$ \\
\hline
\end{tabular}

Fonte: Elaborado a partir dos resultados do modelo.

NT: Não Testado NS: Não significativo a $5 \%$.

Este mesmo resumo é apresentado de forma oposta nas tabelas 5.1 a 5.3, isolando a variável explicada. Na primeira a variável Bolsa sofre influência dela defasada e do risco-país, com destaque para o terceiro período quando ela passa a ser explicada pelo fluxo. A Tabela 5.2 traz o fluxo sendo explicado principalmente pelo câmbio e pela própria variável defasada, com a interferência mais forte da bolsa no segundo período, que é o único de tendência de alta.

TABELA 5.1 - RESUMO DAS VARIÁVEIS QUE EXPLICAM BOLSA

\begin{tabular}{lcccccc}
\hline & \multicolumn{2}{c}{$1999-2002$} & \multicolumn{2}{c}{$2003-2007$} & \multicolumn{2}{c}{$2008-2012$} \\
& $\begin{array}{c}\text { Bolsa } \\
\text { US\$ }\end{array}$ & Bolsa N & $\begin{array}{c}\text { Bolsa } \\
\text { US } \$\end{array}$ & Bolsa N & $\begin{array}{c}\text { Bolsa } \\
\text { US } \$\end{array}$ & Bolsa N \\
\hline Embi+ (-1) & NT & $-0,4650^{* * * *}$ & NT & $-0,3628^{* * *}$ & $-0,5725^{* * *}$ & $-0,4028^{* * *}$ \\
Saídas(-1) & NS & NT & NS & NT & NS $^{* *}$ & NT \\
Ingresso(-1) & NS & NT & NS & NT & $0,1156^{* *}$ & NT \\
Câmbio(-1) & NT & NS & NT & NS & NT & NS \\
BolsaUS $\$(-1)$ & $0,9104^{* * *}$ & NT & $0,9207^{* * *}$ & NT & $0,3774^{* * *}$ & NT \\
Bolsa & NT & NS & NT & NS & NT & NS \\
Nominal (-1) & NT & & & & & \\
\hline
\end{tabular}

Fonte: Elaborado a partir dos resultados do modelo.

NT: Não Testado NS: Não significativo a $5 \%$. NS ${ }^{* *}$ : Significativo no teste de Granger a $5 \%$. 
TABELA 5.2 - RESUMO DAS VARIÁVEIS QUE EXPLICAM FLUXO

\begin{tabular}{|c|c|c|c|c|c|c|}
\hline & \multicolumn{2}{|c|}{ 1999-2002 } & \multicolumn{2}{|c|}{$2003-2007$} & \multicolumn{2}{|c|}{ 2008-2012 } \\
\hline & Ingresso & Saída & Ingresso & Saída & Ingresso & Saída \\
\hline Embi+ $(-1)$ & NT & NT & NT & NT & $-0,7039^{* * *}$ & $\mathrm{NS}^{* * *}$ \\
\hline Saídas(-1) & NS & $0,4504^{* * *}$ & NS & NS & NS & $0,5676^{* * *}$ \\
\hline Ingresso(-1) & $0,3977^{* * *}$ & NS & NS & $\mathrm{NS}^{* * *}$ & $0,5439^{* *}$ & NS \\
\hline Câmbio(-1) & $-0,8068^{* *}$ & $\mathrm{NS}^{* *}$ & $-3,6713^{* * *}$ & $-2,9234^{* * *}$ & NS & $\mathrm{NS}^{* *}$ \\
\hline $\begin{array}{l}\text { Bolsa US } \$ \\
(-1)\end{array}$ & NS & NS & $1,3096^{* * *}$ & $1,1520^{* * *}$ & NS & NS \\
\hline $\begin{array}{l}\text { Bolsa Nomi- } \\
\text { nal (-1) }\end{array}$ & NT & NT & NT & NT & NT & NT \\
\hline
\end{tabular}

Fonte: Elaborado a partir dos resultados do modelo.

NT: Não Testado NS: Não significativo a $5 \%$. NS**: Significativo no teste de Granger

TABELA 5.3 - RESUMO DAS VARIÁVEIS QUE EXPLICAM CÂMBIO

\begin{tabular}{lccc}
\hline & $1999^{-2002}$ & $2003^{-2007}$ & $2008-2012$ \\
\hline Embi+ (-1) & $0,3206^{* * *}$ & $0,175^{* * *}$ & $0,2684^{* * *}$ \\
Saídas(-1) & $\mathrm{NS}$ & $-0,065^{* * *}$ & $\mathrm{NS}$ \\
Ingresso(-1) & $\mathrm{NS}$ & $\mathrm{NS}$ & $\mathrm{NS}$ \\
Câmbio(-1) & $1,0047^{* * *}$ & $0,8295^{* * *}$ & $\mathrm{NS}$ \\
Bolsa US $\$(-1)$ & $\mathrm{NT}$ & $\mathrm{NT}$ & $\mathrm{NT}$ \\
Bolsa Nominal & $-0,1582^{* *}$ & $\mathrm{NS}$ & $\mathrm{NS}$ \\
$(-1)$ & & & \\
\hline
\end{tabular}

Fonte: Elaborado a partir dos resultados do modelo.

NT: Não Testado NS: Não significativo a $5 \%$. NS ${ }^{* *}$ : Significativo no teste de Granger

Por fim, a Tabela 5.3 traz as variáveis que explicam o câmbio, apresentando em todos os períodos o risco-país com relação direta e inelástica, e coeficiente médio de $0,25 \%$ dada uma variação de $1 \%$ no risco-país. Nos dois primeiros períodos o câmbio é influenciado por ele próprio com uma defasagem, mas no terceiro esta continuidade se rompe. No primeiro e no terceiro período verifica-se bolsa influenciando câmbio, o que permite inferir que a valorização no segundo período não tem o mesmo efeito sobre o câmbio que tem a sua desvalorização nos outros dois. Em outras palavras, a queda do Ibovespa parece exercer pressão sobre o câmbio, mas sua alta não. 
É importante destacar que o coeficiente da bolsa sobre o câmbio é de -o,16 no primeiro período, e de -0,12 no terceiro período não significativo estatisticamente. Comparado à elasticidade da influência do risco-país, pode-se observar que esta afeta o câmbio em maior magnitude. O risco-país medido pelo JP Morgan Chase é também uma medida de quanto o Tesouro brasileiro precisa remunerar acima no Treasury Bond para compensar o risco. Neste sentido, assumindo o Embi+ como diferencial de juros, cabe ressaltar que o peso dos juros sobre o câmbio é mais expressivo que o da bolsa.

Outra questão importante diz respeito à relação de causalidade da bolsa sobre o câmbio, que não se verifica na relação do fluxo de saídas sobre o câmbio. Uma vez que a interferência de fato da queda da bolsa deveria ser transmitida para o câmbio através da saída do IERV, abre-se uma lacuna onde a relação de causalidade tem motivações diferentes destas analisadas, ou seja, no primeiro e no terceiro períodos a bolsa explica câmbio, que por sua vez, explica fluxo, mas o contrário não ocorre.

FIGURA 11 - RELAÇÃO DE CAUSALIDADE OBTIDA NO MODELO VAR E NO TESTE DE GRANGER

Período 1999 - 2002:

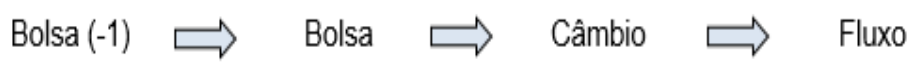

Período 2003 - 2007:

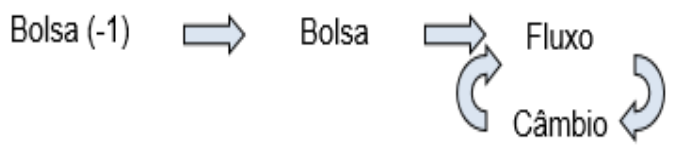

Período 2008 - 2012:

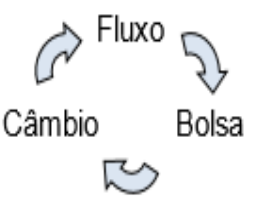

Considerações Finais

A problemática central deste trabalho pode ser resumida na busca por evidências que apontem para uma relação entre investimento estrangeiro em renda variável e taxa de câmbio, compreendendo as influências que exercem simultaneamente com Ibovespa e diferencial da taxa de juros, no período 
iniciado com a flutuação da taxa do câmbio em 1999.

De forma geral, os estudos existentes abordam a influência que o capital externo para renda fixa exerceu sobre a taxa de câmbio na década de 1990; os efeitos da flutuação de capital sobre as economias emergentes e motivos que justificariam a adoção de ferramentas para controle do influxo de capitais; quais os fatores ponderados pelo investidor estrangeiro na tomada de decisão, tendo como variáveis explicativas a taxa de câmbio e o diferencial de juros, além da expressiva participação do investidor estrangeiro sobre a variação do Ibovespa. Em outras palavras, estes estudos apresentaram uma relação de causalidade de juros sobre o câmbio, e de câmbio sobre bolsa em sentido único. Como o investimento estrangeiro para renda variável se avolumou na última década, abre-se a possibilidade de testar as relações no sentido oposto.

Apoiada nos estudos já existentes, a abordagem empírica proposta buscou reunir as variáveis Ibovespa, taxa de câmbio, fluxo de IERV e risco país para analisar as relações de influência e causalidade de umas sobre as outras simultaneamente, empregando modelagem VAR, testes de causalidade de Granger e funções impulso-resposta. As variáveis foram analisadas em duplas (fluxo-câmbio, fluxo-bolsa e bolsa-câmbio, com o risco país exógeno) e fracionadas em 3 períodos (1999-2002, 2003-2007 e 2008-2012) devido às quebras de tendência nas variáveis.

Os resultados apontaram relações diferentes nos 3 períodos, cada uma sendo explicada pelo contexto macroeconômico. No primeiro período a relação de causalidade inicia com a bolsa defasada justificando o presente, que por sua vez explica a variável câmbio, e esta por fim explica fluxo. Confirma-se a bibliografia que aponta o câmbio como causa do fluxo, e acrescenta-se a variável bolsa explicando câmbio.

No segundo período as variáveis câmbio e bolsa explicam fluxo. Trata-se de um período de forte valorização do Ibovespa e do real frente ao dólar, em que o fluxo é atraído de forma elástica pela possibilidade de lucro com a bolsa e com a moeda. Já o terceiro período se assemelha mais ao primeiro do que ao terceiro, visto que se trata de momentos de crise e volatilidade. Surge em 2008 uma relação circular de bolsa-câmbio-fluxo, em que o fluxo passou a explicar bolsa devido ao forte movimento de saída em 2008 por motivações externas, seguido de rápido reingresso em 2009.

Por fim, isola-se o câmbio que é a variável central deste trabalho. Em todos os períodos ela é explicada pelo risco-país, e no primeiro e no terceiro períodos verifica-se bolsa influenciando câmbio. A ausência desta relação no segundo período leva a crer que a valorização da bolsa não tem o mesmo efeito sobre o câmbio que tem a sua desvalorização nos outros dois. Conclui-se, portanto, que existe estatisticamente uma relação de causalidade da bolsa sobre o câmbio em momentos de queda do Ibovespa, confirmando hipótese levantada inicialmente. 
É importante destacar que o efeito da bolsa sobre o câmbio não se dá de maneira direta através do fluxo, uma vez que o fluxo não causa câmbio. A forma mais plausível de se verificar o efeito da bolsa sobre o câmbio em momentos de queda deveria ser pela saída do investidor externo, mas esta hipótese não se confirma estatisticamente. Não há como se afirmar o motivo de tal relação com as variáveis estudadas, mas fica a possibilidade de que seja pela formação de expectativas nos períodos em que há aumento da percepção de risco. Como já existem estudos que apontam para a formação do câmbio no mercado de derivativos antes do spot, poderia ser este o mecanismo de transmissão de tais expectativas.

Com relação à hipótese levantada de que o IERV poderia exercer influência sobre o câmbio superior a da renda fixa, constatou-se que os coeficientes da bolsa sobre o câmbio são menos elásticos que os do risco-país, que é também o diferencial de juros. Conclui-se, portanto, que o peso dos juros sobre o câmbio permanece mais expressivo que o da bolsa na última década.

\section{Referências Bibliográficas}

AGENOR, Pierre-Richard. (1998) Capital inflows, external shocks, and the real exchange rate. Journal of International Money and Finance, 17, pg. 713-740.

ARAUJO, Márcio S.; ARAUJO, Eliane C.; BRUNO, Miguel A. P.. Fluxo de divisas, reservas internacionais e determinação da taxa de câmbio no Brasil: novas evidências para o período 2003-2009. Anais do III Encontro da Associação Keynesiana Brasileira, 2010

ATHUKORALA, Prema-chandra; RAJAPATIRANA, Sarath. (2003) Capital inflows and the real exchange rate: a comparative study of Asia and Latin America. The World Economy, v. 26, n. 4, p. 613-637, 2003.

BANCO CENTRAL DO BRASIL (BCB). Sistema gerenciador de séries temporais (SGS).v. 2.o, Módulo público. [Brasília]: 1947-. Disponível em: <https://www3. bcb.gov.br/sgspub/localizarseries/localizarSeries.do?method=prepararTelaLo calizarSeries > . Acesso em 2012.

Série histórica do balanço de pagamentos. [Brasília]: 1947-. Disponível em: <http://www.bcb.gov.br/?SERIEBALPAG>. Acesso em 2012.

BUENO, Rodrigo L. S. (2008). Econometria de Séries Temporais. São Paulo: Cengage Learning.

CALLADO, Antonio A. C.; AMARAL, Brenda M. (2005). Fluxos de capitais internacionais de investidores institucionais para o Brasil: um estudo sobre os fatores de atração e repulsão. Cadernos de Pesquisa em Administração. São Paulo, v.12, n.2, abril/junho, p. 37-48.

CALVO, Guillermo A.; LEIDERMAN, Leonardo; REINHART, Carmen M. (1993) Capital Inflows and Real Exchange Rate Appreciation in Latin America: The 
Role of External Factors. Staff Papers - International Monetary Fund, Vol. 40, No. 1 (Mar., 1993), PP. 108-151.

CARDODO, Carlos de Almeida; VIEIRA, Flávio Vilela. Câmbio, Inflação e Juros na Transição do Regime Cambial Brasileiro: Uma Análise de Vetores Auto-regressivos e Causalidade; in Anais do XXXIII Econtro Nacional de Economia - Anpec (www.anpec.org.br), Brasília, 2005. Disponível em: http://www.anpec. org.br/encontro_2005.htm

CARNEIRO, R. (2003). A política macroeconômica da era FHC ao governo Lula: da trindade impossível à autonomia necessária. In: REIS VELLOSO (Org.). Governo Lula: novas prioridades e desenvolvimento sustentado. Rio de Janeiro: José Olympio. 559p.

EDWARDS, Sebastian. (1998) Capital Flows, Real Exchange Rates, and Capital Controls: Some Latin American Experiences. NBER Working Paper, no 6800. Cambridge MA, November 1998.

ENDERS, Walter (2010). Applied Econometric Time Series. 3rd Ed. University of Alabama: Wiley.

FRANZEN, A.; MEURER, R.; GONÇALVES, C. E. S.; SEABRA, F. (2009) Determinantes do fluxo de investimentos de portfólio para o mercado acionário brasileiro. Estudos Econômicos, São Paulo, v. 39, n. 2, p. 301-328, Abril-Junho 2009.

ITO, Takatoshi. (2000) Capital Flows in Ásia, in EDWARDS, S. (ed.), Capital Flows and the Emerging Economies: Theory, Evidence, and Controversies. Chicago: University of Chicago Press, pg. 255-298.

KAPLAN, Ethan; RODRIK, Dani (2001). Did the Malaysian Capital Controls Work? NBER Working Paper No. 8142. Cambridge MA, February 2001.

KWIATKOWSKI,D.; PHILLIPS, P.C.B.; SCHMIDT, P.; SHIN, Y. (1992). Testing the null hypothesis of stationary against the alternative era unit root: How sure are we that economic time series have a unit root? Journal of Econometrics, v. 54, p. 159-178.

MADDALA, G. S.; KIM, In-Moo (2004). Unit Roots, Cointegration and Structural Change. Cambridge University Press, $6^{\mathrm{a}}$ Ed.

MEURER, Roberto. (2005) Fluxo de Capital Estrangeiro e Desempenho do Ibovespa. Revista Brasileira de Finanças, Vol. 4, No. 1, pp. 345-361.

PHILLIPS, P.C.B.; PERRON, P. (1988). Testing for a unit root in time series regression. Biometrika, v. 75 (2), p. 335-346.

PINHEIRO, Alessandro M.; AMIN, Mario M. (2004). Fluxos de capitais e componentes macroeconômicos: análise de inter-relações através da aplicação de um modelo de vetores auto-regressivos (VAR). Essa.

PINTO, Ana C. B.; VIEIRA, Flávio V. (2008). Câmbio flexível e metas de inflação em países selecionados da América Latina: análise de vetores auto-regressivos (VAR). Ensaios FEE, Porto Alegre, v.29, n.1, p.65-100, jun. 2008.

SILVAJR, A. (2010). Brazilian Strategy for Managing the Risk of Foreign Exchange Rate Exposure During a Crisis. Banco Central do Brasil Working Paper Series, (207).

SOIHET, E. Índice de controle de capitais: uma análise de legislação e dos determi- 
nantes ao fluxo de capital no Brasil no período de 1990-2000. Dissertação (Mestrado) - Escola de Pós-Graduação em Economia, FGV, Rio de Janeiro, 2002.

Recebido em : 12 de outubro de 2013 Aceito em: 14 de maio de 2014 
